\title{
Evaluation of anxiety level changes during the first three months of orthodontic treatment
}

\section{Ersin Yıldırım \\ Seniz Karacay}

GMMA Haydarpasha Training Hospital, Section of Orthodontics, Istanbul, Turkey
Objective: To determine the changes in dental anxiety, state anxiety, and trait anxiety levels of patients and their parents after 3 months of active orthodontic treatment. Methods: We evaluated 120 patients and one parent of each patient. State Anxiety (STAI-S), Trait Anxiety (STAI-T), and Corah's Dental Anxiety Scale (DAS) were administered before orthodontic treatment (T1) and after 3 months of treatment (T2). Differences in scores between T1 and T2 were compared using paired-sample t-tests and the relationship between the scores of the DAS and the STAI were analyzed using a bivariate two-tailed Pearson correlation test. Results: Dental anxiety and state anxiety levels decreased among the patients after adjustment to orthodontic treatment $(p<0.001)$. However, 3 months of treatment was not sufficient to decrease the anxiety levels of parents $(p>0.05)$. Patient trait anxiety affected patient state anxiety and dental anxiety $(p<0.01)$. Additionally, a significant correlation was found between patient dental anxiety and parent dental anxiety $(p<0.05)$. Conclusions: Dental anxiety and state anxiety levels decrease after patients become familiar with their orthodontist and they became accustomed to orthodontic treatment. However, 3 months is not a sufficient length of time to decrease parental anxiety levels.

[Korean J Orthod 2012;42(4):201-206]

Key words: Psychology, Behavioral sciences, Compliance, Orthodontic treatment

Received February 11, 2012; Last Revision March 22, 2012; Accepted March 26, 2012.

Corresponding author: Seniz Karacay.

Associate Professor, GMMA Haydarpasha Training Hospital, Section of Orthodontics, Tibbiye Cad., GATA Haydarpasa Egt. Hast., Diş Servisi, Ortodonti Bolumu, Uskudar, İstanbul 34000, Turkey.

Tel+90-5422020 e-mail kseniz@yahoo.com

The authors report no commercial, proprietary, or financial interest in the products or companies described in this article.

(C) 2012 The Korean Association of Orthodontists.

This is an Open Access article distributed under the terms of the Creative Commons Attribution Non-Commercial License (http://creativecommons.org/licenses/by-nc/3.0) which permits unrestricted non-commercial use, distribution, and reproduction in any medium, provided the original work is properly cited. 


\section{INTRODUCTION}

Anxiety is a set of behavioral manifestations that is divided into two subgroups: state anxiety and trait anxiety. State anxiety is a transitory emotional condition that varies in intensity according to the environmental conditions. State anxiety reflects an individual's present anxiety and fluctuates over time, depending on the intensity of pressure. Trait anxiety, however, is a personality trait that reflects an individual's general baseline anxiety and remains relatively stable. ${ }^{1}$

Dental anxiety is a widespread problem that results in a significant barrier to the receipt of dental care. ${ }^{2}$ Dental anxiety was first studied by Shoben and Borland ${ }^{3}$ who explained that this avoidance behavior results from unfavorable attitudes toward dentists on the part of family members and a history of painful dental experiences. When dental anxiety is a result of the unfavorable attitudes of family members, it is the result of indirect or direct conditioning experiences. When due to a history of painful dental experiences, it is a component of a constitutional vulnerability to anxiety disorders that manifests as general anxiety states, mood disorders, and multiple severe fears. ${ }^{4}$ Dental anxiety not only leads to avoidance of dental care, but it may also affect individuals generally by causing sleep disturbance, negative thoughts, and feelings of low self-esteem and confidence. ${ }^{5}$

Several authors have attributed dental anxiety to the expectation of pain. ${ }^{6,7}$ However, despite advances in dental equipment and treatment procedures that control pain, studies have revealed that these innovations did not decrease the fear of pain that is associated with dentistry. Moreover, the incidence of dental anxiety is reported to have increased from $4 \%^{7}$ to $23 \%{ }^{8}$ of the general population over the past 33 years. Dental anxiety and fear appears to vary according to type of treatment. Periodontal or endodontic treatments have been shown to cause higher levels of anxiety than restorative or prophylactic treatments. ${ }^{9,10}$ Results of studies examining dental anxiety level and gender are conflicting. Bergdahl and Bergdahl, ${ }^{11}$ and Hakeberg et al. ${ }^{12}$ reported higher levels of dental anxiety among females, but Sari et al. ${ }^{13}$ did not find any such difference between genders.

In the orthodontic literature, there have been a few studies that have evaluated the anxiety levels of patients undergoing orthodontic treatment. Crowley et al. ${ }^{14}$ reported that orthodontic treatment induced fear and anxiety. Maj et al. ${ }^{15}$ stated that $77 \%$ of children had difficulty psychologically adjusting to orthodontic appliances. Lewis and Brown ${ }^{16}$ found that $25 \%$ of patients were anxious about wearing orthodontic appliances. Breistein and Burden ${ }^{17}$ stated that orthodontic treatment was perceived as one of the least painful dental treatments. Wright et al. ${ }^{18}$ reported that although supplemental written information resulted in improved motivation for orthodontic treatment, it had no significant effect on anxiety and apprehension. Sari et al. ${ }^{13}$ found that patients awaiting orthodontic treatment had high state anxiety levels while those who had been undergoing treatment for 1 year had normal state anxiety levels. However, the trait anxiety levels of the parents of both groups of patients was high.

In the present study, we investigated the short-term alteration of three psychological outcome measures (state anxiety, trait anxiety, and dental anxiety) experienced by patients and one of their parents before and after 3 months of orthodontic treatment. Our goal was to determine whether patient and parent anxiety levels decreased after patients and their parents became familiar with their orthodontist, and became accustomed to orthodontic treatment procedures. We also evaluated possible correlations between outcome measures and compared outcome measures based on gender.

\section{MATERIALS AND METHODS}

This questionnaire-based longitudinal study consisted of 120 patients (61 females and 59 males, mean age $15.32 \pm$ 1.19 years) with mild class I malocclusion and one parent of each patient (61 females and 59 males, mean age 40.07 \pm 3.97 years). A power analysis established by $G^{\star}$ Power software (v3.1.3; Franz Faul, Universität Kiel, Germany) was used to determine sample size. A sample size of 120 patients was calculated to provide more than $90 \%$ power to detect significant differences with an effect size of 0.30 between the two groups at a 0.05 significance level. All of the patients were treated by the same clinician using a non-extraction fixed orthodontic treatment approach. All participants signed a consent form and it was emphasized that responses were confidential and would not affect treatment in any way.

Patient and parent anxiety levels were determined using questionnaires that were completed individually. The first set of questionnaires was given at the beginning of the initial appointment (T1). After they were completed separately by the patients and their parents, the clinician discussed the nature and extent of the malocclusion with the patients and explained the necessary treatment approach that had been planned. The second set of questionnaires were distributed at the end of the third month of active orthodontic treatment (T2). The two sets of questionnaires were identical and were comprised of two different test versions of the State-Trait Anxiety Inventory (STAI) and Corah's Dental Anxiety Scale (DAS). To eliminate any order effects, half of the participants completed the STAI test before the DAS test, and the other half completed them in the opposite order. 


\section{Questionnaire design}

The questionnaires consisted of two instruments that assessed patient and parent psychological status. In addition, participants were asked to provide demographic information, including age, gender, and occupation, by completing a form provided with the two questionnaires. The following scales were used:

STAI: The STAI was developed by Spielberger et al. ${ }^{19}$ The STAI is a self-report instrument that comprises separate self-report scales measuring two distinct anxiety concepts. These scales measure state anxiety (how one feels at a particular moment; e.g., dental visit) and trait anxiety (how one usually feels). The state anxiety score (STAI-S) is based on 20 items for which respondents rate anxiety on a scale from one (not at all) to four (very much so). The trait anxiety score (STAI-T) is based on 20 questions designed to measure anxiety on a scale from one (almost never) to four (almost always). The STAI has been validated for many situations and populations. ${ }^{20} \mathrm{We}$ used a Turkish version of the STAI. ${ }^{21}$ In this version of the STAI, there are 10 state anxiety-absent items, 10 state anxiety-present items, 7 trait anxiety-absent items, and 13 trait anxiety-present items. The arrangement of anxietypresent and anxiety-absent items is identical to that of the original version. STAI scores range between 20 and 80 for each subscale.

DAS: Dental anxiety was measured using DAS. ${ }^{22}$ It is a brief self-completed questionnaire consisting of four questions asking how respondents would feel "if they had to go to the dentist tomorrow," "waiting at the dentist office," "waiting while he gets the drill ready," and "in the dentist's chair to have teeth cleaned". Respondents rate each item on a five-point scale that ranges from not anxious to extremely anxious, in ascending order. Each question carries a possible maximum score of five, and the total scores range between 4 and 20. We used a Turkish version of this scale. ${ }^{23}$

\section{Statistical methods}

Statistical analyses were performed using the Statistical Package for the Social Sciences (SPSS for Windows, version 15.0, SPSS Inc., Chicago, IL, USA). We applied the Kolmogorov-Smirnov normality test (with Liliefors significance correction) and Levene's variance homogeneity test to the data. The data were found to be normally distributed and there was homogeneity of variance among the groups. The mean anxiety levels and standard deviations (SD) were calculated for $\mathrm{T} 1$ and $\mathrm{T} 2$. We used paired-sample t-tests to compare T1 and T2 scores. We used independent-sample $t$-tests to compare the scores of male and female participants. A bivariate two-tailed Pearson correlation test was conducted in order to analyze the relationship between DAS scores and STAI scores. Internal consistencies for the DAS and two scales of the STAI were evaluated using Cronbach's alpha coefficient. Significance was set at $p<0.05$.

\section{RESULTS}

We evaluated the reliability of the scales used in this study. Reliability of the DAS resulted in a 0.87 alpha value. The STAI-S had a 0.84 alpha value and the STAI-T had a 0.85 alpha value.

Mean patient and parent anxiety values and SD for T1 and T2 are presented in Table 1. Among patients, the mean DAS score $( \pm$ SD) decreased significantly from 8.66 $( \pm 2.10)$ at $\mathrm{T} 1$ to $7.08( \pm 2.52)$ at T2 $(p<0.001)$. Similarly, the mean STAI-S level significantly decreased from 33.18 $( \pm 4.43)$ at $\mathrm{T} 1$ to $28.60( \pm 4.76)$ at $\mathrm{T} 2(p<0.001)$. The mean STAI-T value for these participants also decreased from $37.52( \pm 7.24)$ at $\mathrm{T} 1$ to $36.98( \pm 7.43)$ at $\mathrm{T} 2$, but this decrease was not statistically significant $(p>0.05)$.

Among parents, the mean DAS and STAI-T values ( \pm SD) decreased from $9.52( \pm 3.43)$ at $\mathrm{T} 1$ to $9.38( \pm 3.36)$ at T2 and from $43.03( \pm 6.15)$ at T1 to $42.13( \pm 6.55)$ at T2, respectively. The mean STAI-S value, in contrast, increased from $34.91( \pm 6.82)$ at $\mathrm{T} 1$ to $35.13( \pm 7.67)$ at T2. However, none of these differences were statistically significant $(p>0.05$; Table 1$)$. There was no significant relationship between anxiety and gender $(p>0.05)$.

The Pearson correlation coefficients between DAS, STAI-S, and STAI-T scores at T1 are reported in Table 2. Patient DAS scores were significantly correlated to patient STAI-S scores $(\mathrm{r}=0.249, p<0.01)$ and patient STAI-T scores $(\mathrm{r}=0.366, p<0.01)$. There was also a significant correlation between patient STAI-T scores and STAI-S scores $(r=0.476, p<0.01)$. Similarly, parent DAS scores were significantly correlated to parent STAI-S scores $(r=$

Table 1. Descriptive statistics of dental anxiety and state-trait anxiety scores with results of paired sample t-tests

\begin{tabular}{|c|c|c|c|c|c|c|}
\hline \multirow{2}{*}{ Index (possible range) } & \multicolumn{3}{|c|}{ Patient $(n=120)$} & \multicolumn{3}{|c|}{ Parent $(n=120)$} \\
\hline & T1 & $\mathbf{T 2}$ & $p$-value & T1 & $\mathbf{T} 2$ & $p$-value \\
\hline Dental anxiety (4-20) & $8.66(2.10)$ & $7.08(2.52)$ & 0.000 & $9.52(3.43)$ & $9.38(3.36)$ & 0.146 \\
\hline State anxiety (20-80) & $33.18(4.43)$ & $28.60(4.76)$ & 0.000 & $34.91(6.82)$ & $35.13(7.67)$ & 0.441 \\
\hline Trait anxiety (20-80) & $37.52(7.24)$ & $36.98(7.43)$ & 0.376 & $43.03(6.15)$ & $42.13(6.55)$ & 0.170 \\
\hline
\end{tabular}

Values are presented as mean (stadard deviation).

T1, Prior orthodontic treatment; T2, after 3 months of orthodontic treatment period. 
Table 2. Correlation matrix showing Pearson's correlation coefficient between DAS and STAI scores prior to the start of ongoing orthodontic treatment (T1)

\begin{tabular}{lcccccc}
\hline & Patient DAS & Patient STAI-S & Patient STAI-T & Parent DAS & Parent STAI-S & Parent STAI-T \\
\hline Patient DAS & 1 & & & & & \\
Patient STAI-S & $0.249^{\dagger}$ & 1 & & & & \\
Patient STAI-T & $0.366^{\dagger}$ & $0.476^{\dagger}$ & 1 & & & \\
Parent DAS & $0.261^{\dagger}$ & 0.066 & 0.173 & 1 & & \\
Parent STAI-S & $0.212^{*}$ & -0.141 & 0.023 & $0.340^{\dagger}$ & 1 & 1 \\
Parent STAI-T & 0.175 & 0.024 & 0.040 & $0.303^{\dagger}$ & $0.405^{\dagger}$ & 1 \\
\hline
\end{tabular}

DAS, Dental Anxiety Scale; STAI, State-Trait Anxiety Inventory; STAI-S, state anxiety; STAI-T, trait anxiety.

Correlation is significant at ${ }^{*} p<0.05 ;{ }^{\dagger} p<0.01$.

Table 3. Correlation matrix showing Pearson's correlation coefficient between DAS and STAI scores 3 months after the start of ongoing orthodontic treatment (T2)

\begin{tabular}{lcccccc}
\hline & Patient DAS & Patient STAI-S & Patient STAI-T & Parent DAS & Parent STAI-S & Parent STAI-T \\
\hline Patient DAS & 1 & & & & & \\
Patient STAI-S & 0.158 & 1 & & & & \\
Patient STAI-T & $0.595^{\dagger}$ & $0.687^{\dagger}$ & 1 & & & \\
Parent DAS & $0.319^{\dagger}$ & $0.264^{\dagger}$ & $0.315^{\dagger}$ & 1 & & \\
Parent STAI-S & $0.199^{*}$ & -0.078 & 0.082 & $0.375^{\dagger}$ & 1 & \\
Parent STAI-T & $0.290^{\dagger}$ & -0.168 & -0.013 & $0.204^{*}$ & $0.404^{\dagger}$ & 1 \\
\hline
\end{tabular}

DAS, Dental anxiety scale; STAI, state-trait anxiety inventory; STAI-S, state anxiety; STAI-T, trait anxiety.

Correlation is significant at ${ }^{*} p<0.05 ;{ }^{\dagger} p<0.01$.

$0.340, p<0.01)$ and STAI-T scores $(\mathrm{r}=0.303, p<0.01)$. There was also a significant correlation between parent STAI-T scores and STAI-S scores $(\mathrm{r}=0.405, p<0.01)$. Moreover, patient DAS scores were significantly correlated with parent DAS $(\mathrm{r}=0.261, p<0.01)$ and STAI-S scores $(\mathrm{r}$ $=0.212, p<0.05$ ).

The correlations between DAS, STAI-S, and STAI-T scores at T2 are reported in Table 3. Patient STAI-T scores were significantly correlated to patient DAS scores $(\mathrm{r}=$ $0.595, p<0.01)$ and patient STAI-S scores $(\mathrm{r}=0.687, p<$ 0.01 ). Additionally, patient DAS scores were significantly correlated to parent DAS scores $(r=0.319, p<0.01)$, STAI-S scores $(\mathrm{r}=0.199, p<0.05)$, and STAI-T scores $(\mathrm{r}$ $=0.290, p<0.01)$. Parent DAS scores were significantly correlated to parent STAI-S scores $(\mathrm{r}=0.375, p<0.01)$ and STAI-T scores $(\mathrm{r}=0.204, p<0.05)$. There was also a significant correlation between parent STAI-T scores and STAI-S scores $(\mathrm{r}=0.404, p<0.01)$.

\section{DISCUSSION}

We hypothesized that the anxiety levels of adolescents receiving orthodontic treatment would change after they became accustomed to orthodontic appliances and that this anxiety level would be affected by their parents' attitude. We evaluated the state anxiety, trait anxiety, and dental anxiety levels before orthodontic treatment and after 3 months of orthodontic treatment. We also explored the multidimensionality of patient anxiety through its relationship to parent anxiety.

Spielberger et al. ${ }^{19}$ reported that subjects younger than 14 years of age may not have a balanced psychological character and this should be the minimum age limit for psychology studies. We therefore excluded those patients under 14 years of age from our study. We selected patients for inclusion in the study who had mild class I malocclusion and who needed fixed orthodontic treatment without extraction in order to standardize the study group. Orthodontic treatments were carried out by the same clinician in order to eliminate the positive and negative effects of different doctor-patient relationships on patient psychology.

Assessment tools such as the DAS ${ }^{22}$ and STAI $^{19}$ are commonly used for screening dentally anxious patients. ${ }^{13,20}$ These measures have been shown to have high validity and reliability. In our study, DAS and STAI were used to evaluate the anxiety levels of the patients and their parents. We included parents in this study because, according to Spielberger et al., ${ }^{19}$ anxiety is a contagious emotion; the voice, glances, and psychological state of 
anxious parents can affect a child's emotional condition.

Dental anxiety studies have shown that anxious patients who have completed behavioral-cognitive therapy were less likely to cancel appointments, more likely to complete more fear-provoking treatments, and more able to maintain regular dental care. ${ }^{18}$ Other researchers have examined depression or moodiness in association with anxiety in studies of patient avoidance and compliance patterns. ${ }^{19,20}$ Irregular dental attendance may play a major role in increasing levels of dental anxiety. ${ }^{21}$ Dental anxiety is also related to personality and psychological status. ${ }^{21,22}$ This might form the basis for explaining the presence of higher levels of anxiety at the beginning of active orthodontic treatment in this study. At the end of the third month of orthodontic treatment, patient dental anxiety and state anxiety levels were lower than they were before the first orthodontic appointment because they were familiar with their orthodontist and had become accustomed to the fixed orthodontic appliances. However, the change in patient trait anxiety score was insignificant. Trait anxiety reflects the general anxiety of patients and describes their long-term anxiety. Three months of orthodontic treatment was therefore unlikely to affect its level. None of the scores changed for the parents in our study over the three-month study period. These findings agree with those of Sari et al. ${ }^{13}$ During treatment sessions, only patients were taken into the clinic. The parents stayed in the waiting room during the sessions. The clinician described the treatment approach to the patients, and provided them with dental health education and motivation at each visit. In our opinion, the observed decrease in the anxiety of the patients resulted from this motivation. Sergl et al. ${ }^{24}$ reported that information about necessary treatment may allow patients to feel greater emotional control and to perceive less discomfort during orthodontic treatment. Because the parents were not commonly present during the description of treatment, the unchanged anxiety levels of the parents in this study was probably due to the lack of information they received about the orthodontic treatment. If sufficient information and motivation were given to the parents, and the treatment procedure was clarified during appointments, the anxiety levels of the parents might decrease.

Although many authors have reported that dental anxiety is more common in women than in men, ${ }^{6,25}$ we found no relationship between gender and dental or statetrait anxiety levels in the present study. Locker et al. ${ }^{8}$ and Sari et al. ${ }^{13}$ similarly found no association between gender and dental anxiety. The type of treatment, however, affects the level of anxiety and fear. Restorative or prophylactic treatments are reported to cause lower levels of anxiety than periodontal or endodontic treatments. ${ }^{9,10}$ Participants of both genders in our study perceived orthodontic treatment as a less painful treatment approach than other forms of dental treatment.

The results of our study revealed that a significant relationship between dental anxiety and state-trait anxiety exist. Patient trait anxiety prior to treatment was correlated with patient dental anxiety and patient state anxiety. Additionally, parent dental anxiety was also correlated with parent state anxiety and parent trait anxiety. These findings are consistent with the results of Fuentes et al., ${ }^{26}$ who reported an association between DAS and STAI-T. We also found a significant correlation between patient dental anxiety and parent dental and state anxiety. This correlation remained after 3 months of orthodontic treatment. This finding is supported by Spielberger and colleague's ${ }^{19}$ definition of anxiety as a contagious emotion. Gordis et al. ${ }^{27}$ also reported that the anxiety traits in children and adolescents are related to familial attitude. Similarly, Kashani et al. ${ }^{28}$ showed that perceived family characteristics may have an effect on a child's anxiety.

We used self-report measures of anxiety levels in our study. Although Spielberger et al. ${ }^{19}$ reported the limitations of self-report methodologies, this type of measure has been routinely used in medical settings. Heaton et $\mathrm{al}^{29}$ found a significant relationship between self-reported and observed measures of dental anxiety. Formal dental fear assessments are rarely used in clinical practice. ${ }^{30}$ Practitioners may believe that asking questions about anxiety could increase patients' fear of dental care. However, Corah ${ }^{31}$ reported that patient satisfaction improved when dentists inquired about their anxiety and argued that if a patient was not anxious, asking about anxiety would not produce it. Corah further stated that asking about anxiety may provide patients an opportunity to express any concerns. Good dental health education, regular dental visits, good patient-dentist relationships, and suitable communication with patients may all contribute to the control of dental anxiety.

\section{CONCLUSION}

1. Patient dental anxiety and state anxiety levels decrease after patients become familiar with their orthodontist and become accustomed to orthodontic treatment.

2. Patient trait anxiety affects the patient state anxiety and dental anxiety. Additionally, patient dental anxiety is correlated with parent dental anxiety and state anxiety.

3. Gender affects neither the anxiety levels of the patients undergoing orthodontic treatment nor the anxiety levels of their parents.

\section{REFERENCES}

1. Caumo W, Broenstrub JC, Fialho L, Petry SM, Brathwait $\mathrm{O}$, Bandeira $\mathrm{D}$, et al. Risk factors for postope- 
rative anxiety in children. Acta Anaesthesiol Scand 2000;44:782-9.

2. Levitt J, Mcgoldrick P, Evans D. The management of severe dental phobia in an adolescent boy: a case report. Int J Paediatr Dent 2000;10:348-53.

3. Shoben EJ Jr, Borland L. An empirical study of the etiology of dental fears. J Clin Psychol 1954;10:171-4.

4. Weiner AA, Sheehan DV. Etiology of dental anxiety: psychological trauma or CNS chemical imbalance? Gen Dent 1990;38:39-43.

5. Cohen SM, Fiske J, Newton JT. The impact of dental anxiety on daily living. Br Dent J 2000;189:385-90.

6. Dinjian MD. The psychic factor in dental practice. Dent Surg 1921;17:471-5.

7. Vassend O. Anxiety, pain and discomfort associated with dental treatment. Behav Res Ther 1993;31:659-66.

8. Locker D, Liddell A, Shapiro D. Diagnostic categories of dental anxiety: a population-based study. Behav Res Ther 1999;37:25-37.

9. Stabholz A, Peretz B. Dental anxiety among patients prior to different dental treatments. Int Dent J 1999;49: 90-4.

10. Wong M, Lytle WR. A comparison of anxiety levels associated with root canal therapy and oral surgery treatment. J Endod 1991;17:461-5.

11. Bergdahl M, Bergdahl J. Temperament and character personality dimensions in patients with dental anxiety. Eur J Oral Sci 2003;111:93-8.

12. Hakeberg M, Berggren U, Carlsson SG. Prevalence of dental anxiety in an adult population in a major urban area in Sweden. Community Dent Oral Epidemiol 1992;20:97-101.

13. Sari Z, Uysal T, Karaman AI, Sargin N, Ure O. Does orthodontic treatment affect patients' and parents' anxiety levels? Eur J Orthod 2005;27:155-9.

14. Crowley RE, Klebanoff SG, Singer JL, Napoli PJ. Relationship between personality factors and cooperation in dental treatment. J Dent Res 1956;35:157-65.

15. Maj G, Grilli AT, Belletti MF. Psychologic appraisal of children facing orthodontic treatment. Am J Orthod 1967;53:849-57.

16. Lewis HG, Brown WA. The attitude of patients to the wearing of a removable orthodontic appliance. $\mathrm{Br}$ Dent J 1973;134:87-90.

17. Breistein B, Burden DJ. Equity and orthodontic treatment: a study among adolescents in Northern Ireland. Am J Orthod Dentofacial Orthop 1998;113: 408-13.

18. Wright NS, Fleming PS, Sharma PK, Battagel J.
Influence of supplemental written information on adolescent anxiety, motivation and compliance in early orthodontic treatment. Angle Orthod 2010;80:329-35.

19. Spielberger CD, Gorsuch RL, Lushene RE. Manual for the state-trait anxiety inventory. Palo Alto CA: Consulting Psychologists Press; 1970.

20. Okun A, Stein RE, Bauman LJ, Silver EJ. Content validity of the psychiatric symptom index, ces-depression scale, and State-Trait Anxiety Inventory from the perspective of DSM-IV. Psychol Rep 1996;79: 1059-69.

21. Oner N, Le Compte A. Handbook of state and trait anxiety inventory (in Turkish). Istanbul: Boğaziçi University Press; 1983.

22. Ilgüy D, Ilgüy M, Dinçer S, Bayirli G. Reliability and validity of the modified dental anxiety scale in Turkish patients. J Int Med Res 2005;33:252-9.

23. Corah NL. Development of a dental anxiety scale. J Dent Res 1969;48:596.

24. Sergl HG, Klages U, Zentner A. Pain and discomfort during orthodontic treatment: causative factors and effects on compliance. Am J Orthod Dentofacial Orthop 1998;114:684-91.

25. Liddell A, Locker D. Gender and age differences in attitudes to dental pain and dental control. Community Dent Oral Epidemiol 1997;25:314-8.

26. Fuentes D, Gorenstein C, Hu LW. Dental anxiety and trait anxiety: an investigation of their relationship. $\mathrm{Br}$ Dent J 2009;206:E17.

27. Gordis EB, Margolin G, John RS. Parents' hostility in dyadic marital and triadic family settings and children's behavior problems. J Consult Clin Psychol 2001;69:727-34.

28. Kashani JH, Suarez L, Jones MR, Reid JC. Perceived family characteristic differences between depressed and anxious children and adolescents. J Affect Disord 1999;52:269-74.

29. Heaton LJ, Carlson CR, Smith TA, Baer RA, de Leeuw R. Predicting anxiety during dental treatment using patients'self-reports: less is more. J Am Dent Assoc 2007;138:188-95.

30. Dailey YM, Humphris GM, Lennon MA. The use of dental anxiety questionnaires: a survey of a group of UK dental practitioners. Br Dent J 2001;190:450-3.

31. Corah NL. Dental anxiety. Assessment, reduction and increasing patient satisfaction. Dent Clin North Am 1988;32:779-90. 